\title{
DOWNFLOW code and LIDAR technology for lava flow analysis and hazard assessment at Mount Etna
}

\author{
Massimiliano Favalli ${ }^{\star}$, Simone Tarquini and Alessandro Fornaciai
}

Istituto Nazionale di Geofisica e Vulcanologia, Sezione di Pisa, Pisa, Italy

\author{
Article history \\ Received November 23, 2010; accepted April 30, 2011. \\ Subject classification: \\ Volcanic risk, Geomorphology, Algorithms and implementation, Statistical analysis, Data processing.
}

\begin{abstract}
The use of a lava-flow simulation (DOWNFLOW) probabilistic code and airborne light detection and ranging (LIDAR) technology are combined to analyze the emplacement of compound lava flow fields at Mount Etna (Sicily, Italy). The goal was to assess the hazard posed by lava flows. The LIDAR-derived time series acquired during the 2006 Mount Etna eruption records the changing topography of an active lava-flow field. These shorttime-interval, high-resolution topographic surveys provide a detailed quantitative picture of the topographic changes. The results highlight how the flow field evolves as a number of narrow (5-15 $\mathrm{m}$ wide) disjointed flow units that are fed simultaneously by uneven lava pulses that advance within formed channels. These flow units have widely ranging advance velocities $(3-90 \mathrm{~m} / \mathrm{h})$. Overflows, bifurcations and braiding are also clearly displayed. In such a complex scenario, the suitability of deterministic codes for lava-flow simulation can be hampered by the fundamental difficulty of measuring the flow parameters (e.g. the lava discharge rate, or the lava viscosity of a single flow unit). However, the DOWNFLOW probabilistic code approaches this point statistically and needs no direct knowledge of flow parameters. DOWNFLOW intrinsically accounts for complexities and perturbations of lava flows by randomly varying the preeruption topography. This DOWNFLOW code is systematically applied here over Mount Etna, to derive a lava-flow hazard map based on: (i) the topography of the volcano; (ii) the probability density function for vent opening; and (iii) a law for the expected lava-flow length for all of the computational vents considered. Changes in the hazard due to the recent morphological evolution of Mount Etna have also been addressed.
\end{abstract}

\section{Introduction}

During effusive events, lava flows move downhill according to the local topography. As lava is a fluid in motion under the influence of gravitational force, these lava flows are largely influenced by the local steepest descent paths. As a lava flow progresses, it also modifies the topography itself. Whatever the type of lava flow (e.g. pahoehoe or a'a'), the flowing lava builds its own solid structures, such as levees or frozen flow units, and forms a new topography over which the newly emitted lavas will flow [e.g. Wadge 1978].
At Mount Etna (Sicily, Italy), lava flows usually evolve into compound lava-flow fields [e.g. Guest et al. 1987, Kilburn and Lopes 1988, Calvari and Pinkerton 2002]. These fields are made of a number of flow units that form during the same effusive event, owing to a pulsed lava supply, to topography-induced bifurcations, to overflows, and so forth [e.g. Lautze et al. 2004, Bailey et al. 2006]. Flow units formed after the emplacement of previous flow units will encounter a topography that may have changed drastically with respect to the pre-eruption topography. Indeed, the emplacement of a compound lavaflow field is deeply influenced by this fundamental parameter, the topography, which is intrinsically and continuously modified during the course of the emplacement itself.

Herein, we quantify topography modifications resulting from flow-field emplacement and we address lava-flow paths in a probabilistic way. Our study is based on two approaches: 1) airborne light detection and ranging (LIDAR) technology, to derive detailed digital elevation models (DEMs) of the volcano and to explore the topographic changes due to the emplacement of compound lava-flow fields [Favalli et al. 2009a]; and 2) application of the topography-based lava-flow simulation (DOWNFLOW) probabilistic code to determine the local probability of inundation by future lava flows [Favalli et al. 2005].

From this evidence, a complex picture of the evolution of an actual lava-flow field is outlined. The DOWNFLOW probabilistic code copes well with the observed, multifaceted emplacement mechanisms, and it has been systematically applied to derive a hazard map for lava flow inundation. Local changes in the hazards due to recent morphological modifications of Mount Etna are also addressed.

\section{Lava flow analysis through airborne LIDAR data}

\subsection{Airborne LIDAR basics}

Airborne LIDAR systems are widely applied to produce high-resolution DEMs. A standard airborne LIDAR system 
consists mainly of: i) a laser sensor that emits high frequency pulses (the LIDAR instrument itself); ii) a differential global positioning system (GPS) receiver to determine the location of the laser-scanning system in three-dimensional space; and iii) an inertial navigation system (INS) to monitor the position and orientation of the airborne platform.

The LIDAR transmits light pulses to the ground, and a photodiode detects the pulses that are reflected or scattered back by the target. The travel-time of the light from the scanner to the target and back is used to calculate the distance between the instrument and the ground. Combining these range measurements with the direction of the pulse emission and the position of the emitter, the system provides precise geographical coordinates and elevations for all of the points sampled across the surveyed area [e.g. Baltsavias 1999, Wehr and Lohr 1999, Wagner et al. 2006]. In addition, the return energy of pulses is proportional to the surface reflectance; this is commonly called the intensity, and it is usually also recorded [Höfle and Pfeifer 2007].

LIDAR data are usually affected by systematic errors. When the analysis requires comparisons between LIDARderived DEMs of the same area that were acquired at different times, all of the DEMs need to be matched accurately by minimizing the elevation differences in areas not affected by natural changes. Appropriate methods for correcting and coregistering LIDAR DEMs can be found, for example, in Favalli et al. [2009a, 2010a] and Fornaciai et al. [2010a].

\subsection{Applications}

Airborne LIDAR technology already has extensive use in the support of volcanological studies [e.g. Ventura and Vilardo 2007, Csatho et al. 2008, Favalli et al. 2009a, Fornaciai et al. 2010b]. Considering lava-flow analysis, high-resolution LIDAR data offer several advantages, including: (i) the rapid update of the volcano topography after (and/or during) eruptions; (ii) the enhanced mapping of the lava flows; and (iii) the precise volume calculations of lava-flow field emplacement.

Airborne LIDAR surveys can be carried out affordably and relatively quickly; therefore, they have been used fruitfully to update topography and to quantify morphological changes related to volcanic activities [Neri et al. 2008, Favalli et al. 2009a]. Tarquini and Favalli [2010] quantified the impact of these changes on the determination of lava-flow paths, and in their relative hazard maps. By using pre-eruption and posteruption LIDAR-derived DEMs that were corrected for the systematic errors, Favalli et al. [2009a] calculated the volume of the 2006 lava-flow field on the southwest flank of Mount Etna. Bisson et al. [2009] used LIDAR data to evaluate the volume of buildings at risk in the town of Zafferana Etnea, on the east flank of Mount Etna.

Several studies have used LIDAR-derived DEMs and intensity maps to obtain detailed measurements of lava-flow channels (e.g. levees, dispersed flow zones, overflows).
Mazzarini et al. [2005] carried out a detailed morphometric analysis of an active lava channel at Mount Etna (Italy), while Favalli et al. [2009a] used the same dataset to investigate the morphological evolution of an active portion of the 2004 lava flow. Harris et al. [2007] used the same data to model the thermo-rheological conditions that appeared to be associated with the observed channel-fed unit, with Favalli et al. [2010b] using LIDAR data to map the distal flow segment of the Mount Etna 2001 lava flow. A step forward in the use of short-interval time series of LIDAR DEMs to study the evolution of lava fields was made though analysis of data from the 2006 LIDAR survey at Mount Etna, as discussed in the next section.

\subsubsection{Syn-eruptive time series of LIDAR-derived topography}

An airborne LIDAR survey of Mount Etna on September 16, 2004, was accomplished during effusive activity that had started a few days before and was feeding lava channels in the headwall of the Valle del Bove [Mazzarini et al. 2005, 2007]. Favalli et al. [2009a] carried out an in-depth analysis of the refined data from this survey, and they obtained two topographic datasets that were acquired 76 min apart over a part of the active lava flows. These surveys revealed rapid morphological changes of the lava flows and provided a impressive preliminary picture of an evolving lava-flow field.

The 2004 experiment paved the way for another airborne LIDAR survey that was carried out for Mount Etna on November 17-18, 2006, during the emplacement of a compound lava-flow field [Favalli et al. 2010a]. This survey was specifically designed to acquire several strips of data that covered the active flow field at different times during the two days of the survey. Eleven coincident topographic maps were derived by single, co-registered data-strips that were acquired over time intervals ranging from $15 \mathrm{~min}$ to $25 \mathrm{~h}$. This detailed documentation allowed Favalli et al. [2010a] to quantify the emplacement mechanisms of an Etnean compound lavaflow field with unprecedented accuracy, which included flow bifurcations, the formation of overflows, and flow pulses moving downstream in channeled flow units. The application of the generalized error-propagation formula allowed precise quantification of the lava volumes involved in the morphological evolution observed. The collected measurements provided precise calculations of timeaveraged discharge rates (TADRs) of the lava for each single flow unit and for the overall flow field, in each time interval that was defined by the pair of maps.

Figure $1 \mathrm{~b}$ shows the morphological changes in the flow field that occurred over a period of $2 \mathrm{~h}$ and $33 \mathrm{~min}$, between 08:31 am and 11:04 a.m. (local time) on November 18, 2006. The map reveals six active channels, as well as a number of channel overflows and smaller secondary flows. The active flow channels transported lava with volume rates ranging 

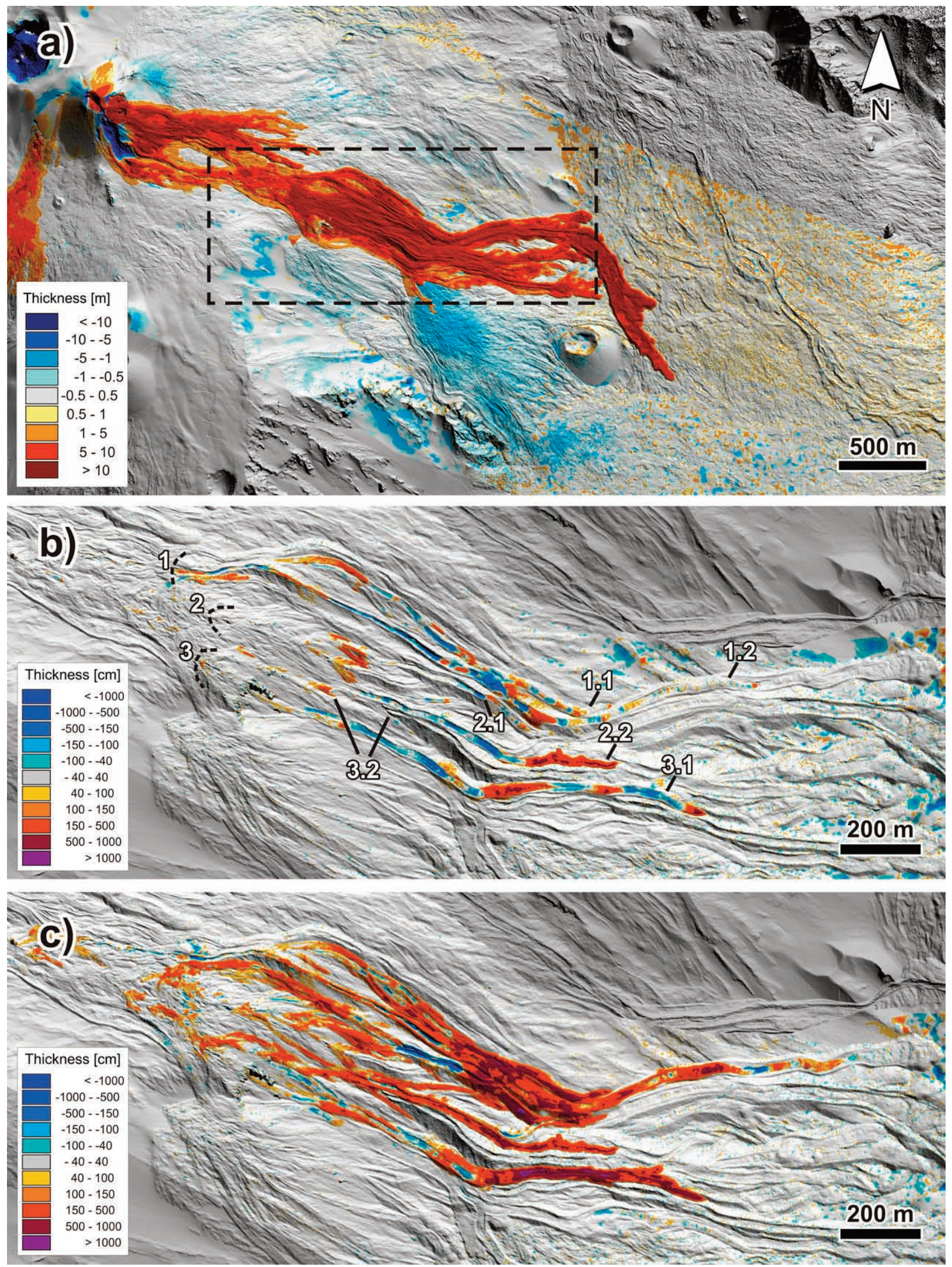

Figure 1. a) 2006-2005 DEM difference map calculated from the LIDAR datasets of INGV-Pisa, showing the extent of the eastern lava field (in warm colors - yellow, orange, red) of the 2006 eruption at the beginning of the 2006 LIDAR survey; b) and c) volumetric changes at the lava-flow field over two different time scales: b) $\sim 2.5$ h, between 08:31 a.m. and 11:04 a.m. on November 18, 2006, and c) $\sim 1$ day, between 10:04 a.m. on November 17, 2006, and 11:04 a.m. on November 18, 2006. Ephemeral vent zones marked 1, 2 and 3 indicate the main feeding points, with the six active channels labeled accordingly (1.1 to 3.2). b) and c) modified from Favalli et al. [2010a]. 
from almost zero (Figure 1b, channel 1.2) up to $3 \mathrm{~m}^{3} / \mathrm{s}$ (Figure $1 \mathrm{~b}$, channel 2.2). These channels were fed by three ephemeral vents (Figure $1 \mathrm{~b}$, vent systems 1 to 3 ) that were distributing the lava at the rate of $4.40 \pm 2.80 \mathrm{~m}^{3} / \mathrm{s}$, as averaged over a 15 min interval. The flow-field emplacement in this short time was complex, with several pulsed-feed, simultaneously active flow units tha overflowed and bifurcated at different points. The paths of the newly formed flow units were strongly influenced by the levees of the older flow units (e.g. channel 1.1), which shows that the paths of later flow units are not determined by the pre-eruption topography alone, especially in a long-lived lava-flow field composed of numerous flow units. Volume pulses propagated downstream in all of the main flow channels [Favalli et al. 2010a]. These induced changes (in time) in the volumetric rates of lava passing through the sections of the lava channels. These were unevenly spaced and unevenly large, and they moved at different velocities. The advancing velocities of different flow fronts were also uneven: flow fronts 1.1 and 2.1 advanced very slowly $(5 \mathrm{~m} / \mathrm{h}$ and $3 \mathrm{~m} / \mathrm{h}$, respectively), flow front $3.1 \mathrm{had}$ a considerably higher velocity $(20 \mathrm{~m} / \mathrm{h})$, and flow front 2.2 advanced at a velocity of $90 \mathrm{~m} / \mathrm{h}$.

Figure $1 \mathrm{c}$ shows the elevation changes that took place over the $\sim 25$-h period between 10:04 a.m. on November 17 and 11:04 a.m. on November 18, 2006. Here, the flow field is formed by several flow units: many flows remained channeled within existing levees to form a flow field of coalesced and overlapping levees and overflow units. By analyzing only Figure 1c, it is impossible to understand the sequence of the flow-unit emplacement. The total volume over the $\sim 25$-h period was $\sim 0.6 \times 10^{6} \mathrm{~m}^{3}$, which gives a time-averaged discharge rate of $6.31 \pm 0.03 \mathrm{~m}^{3} / \mathrm{s}$ for that period (for details, see Favalli et al. [2010a]). The typical channel widths of the flow units of Figure 1b, 1c were between $5 \mathrm{~m}$ and $15 \mathrm{~m}$.

\section{Simulation of lava-flow paths}

\subsection{The DOWNFLOW code}

To study the possible paths of future lava flows and the extent of inundation, we used the DOWNFLOW code, which has already been extensively used in lava-flow hazard applications at basaltic volcanoes, including Mount Etna [Favalli et al. 2009b, 2009c]. Lava flows are gravity-driven flows; for this reason, as a first approximation, they follow the steepest descent path across the underlying topography. However, lava flows tend to spread out, to surmount obstacles, and to branch in multiple directions. The DOWNFLOW model accounts for these complications by tracing a number $\mathrm{N}$ of the steepest descent paths, with each path calculated on a topography where the elevation is varied at each point in a random way in a given range $\pm \Delta h$ [Favalli et al. 2005]. The result of a DOWNFLOW simulation is represented by a map where each point records the number of times $N$ that the lava passed over it.

The two parameters $N$ and $\Delta h$ can be tuned to calibrate the code to different scenarios (e.g. different characteristics of lava flows, different volcanoes). Typically, for $N$ greater than several thousand, the lava-flow invasion areas computed with DOWNFLOW are critically dependent on $\Delta h$, while are only weakly affected by $N$ [Favalli et al. 2009c]. Therefore, $N$ can be fixed to 10,000 , focusing only on the differing $\Delta h$ values. The maximum range of the perturbation, $2 \Delta h$, is an input parameter of the same order of the characteristic vertical length of the lava flow [Favalli et al. 2005].

DOWNFLOW effectively computes the probable paths that a lava flows will follow, but it does not include or solve the complete physical equations governing the phenomenon. Thus, it provides neither insights about the time evolution of the flow nor the flow length. For this reason, computed lava paths always reach the border of the computational DEM, and the maximum lava run-out distance is an additional external constraint, which can be addressed by a statistical analysis of past lava flows [e.g. Lopes and Guest 1982, Favalli et al. 2009b, Favalli et al. 2009d].

\subsection{Model calibration}

The calibration of DOWNFLOW to a specific scenario is performed by tuning $N$ and $\Delta h$ according to real lava flows. To compare simulations with real cases, there is the need for both the precise boundaries of actual lava-flow fields and the pre-eruption topography over which to run the code. The boundaries of all of the recent Mount Etna lava-flow fields are readily available from the literature [e.g. Allard et al. 2006] or from the reports of the Etna monitoring staff (http:/ /www.ct.ingv.it/). For the pre-eruption topography, we collected a series of Mount Etna DEMs for conditions in 1998 [Tarquini et al. 2007], 2004 [Mazzarini et al. 2005], 2005 [Favalli et al. 2009a] and 2006 [Favalli et al. 2010a]. To compare the DOWNFLOW quantitative simulations to the real lava-flow fields, the unconstrained simulated paths were cut to the lengths of the actual lava flows (Figures 2, 3), and to measure the fit, we used the following fitness function $\mu$ [e.g. Rongo et al. 2008]:

$$
\mu=\sqrt{\frac{A_{S} \cap A_{R}}{A_{S} \cup A_{R}}}
$$

where, $A_{S}$ is the area covered by the simulation, and $A_{R}$ is the area covered by the actual lava-flow; and $\mu$ is 1 when the two areas coincide, and 0 when they have no overlap at all.

As an example, Figure 2a shows the DOWNFLOW bestfit simulation for the initial stage of the 2006 effusive activity. The extent of the lava-flow field on the July 24, 2006, is best approximated using $N=10,000$ and $\Delta h=1 \mathrm{~m}$, which obtains a very good fit with a value for $\mu$ of 0.75 . Rather than fitting the initial stages of lava flows, we are much more interested in finding the best fit for the final compound lava fields. 


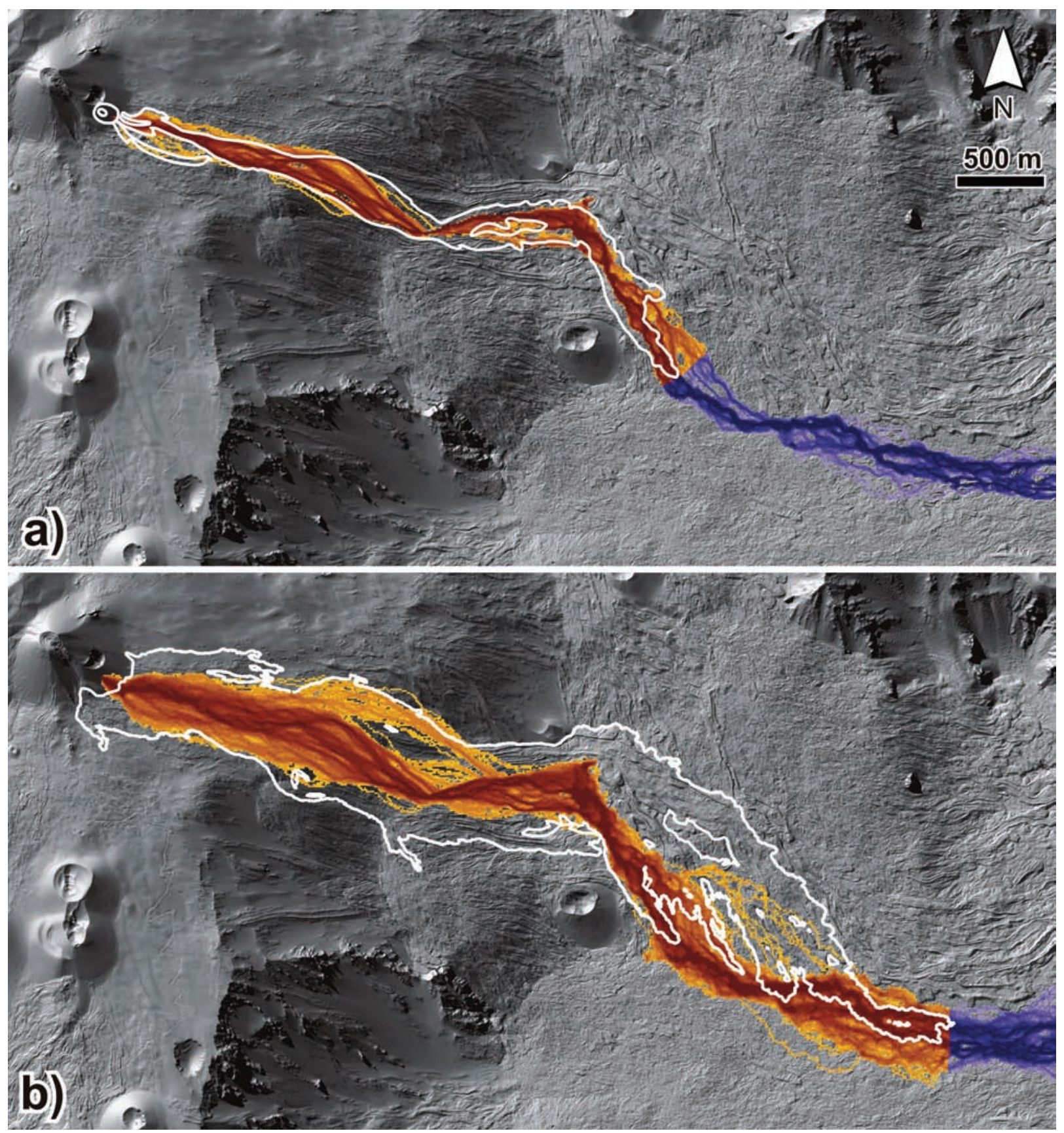

Figure 2. Comparison between real (white lines) and simulated (colored areas) lava-flow paths for the 2006 eastern flow field. Lighter and darker colors, lower and higher frequencies of simulated lava-flow passage, respectively. Red hues, areas located at a distance from the vent lower than the maximum distance attained by the real lava flows. a) DOWNFLOW best-fit simulation (with $\Delta h=1 \mathrm{~m}, \mu=0.75$ ) for the initial stage (up to July 24) of the 2006 effusive activity on the east flank; b) best-fit (with $\Delta h=3 \mathrm{~m}, \mu=0.68$ ) for the final eastern 2006 compound lava fields.

Favalli et al. [2005, 2009b] have already reported on the best calibration for DOWNFLOW at Mount Etna for some final lava-flow fields, where they determined the values of $N=$ 10,000 and $\Delta h=3 \mathrm{~m}$. This calibration has been tested for several of the recent lava-flow field emplacements after 2001 for which the pre-eruption topographies and documented flow-field boundaries are available.

In particular, we focus here on the effusive activity of Mount Etna in 2006, when two lava-flow fields formed on the eastern and western slopes, downhill of the Southeast Crater [Behncke et al. 2008]. In these cases, the standard calibration $(N=10,000$ and $\Delta h=3 \mathrm{~m})$ provides $\mu$ values of
0.68 and 0.77 for the eastern and western 2006 lava-flow fields, respectively (Table 1 ; Figures $2 \mathrm{~b}$ and 3 ). Table 1 shows the $\mu$ values obtained for other more recently lava flows.

In some cases, e.g. the 2002 lava-flow field where the $\mu$ value is only 0.59 (Table 1), only moderate agreement is indicated between reality and the simulation. Nevertheless, the standard calibration values must be considered as average best-fit values, and the $\mu$ values of Table 1 that were obtained with fixed $N$ and $\Delta h$ highlight the overall good performance of the standard calibration. The initial formation of lava-flow fields is instead better described by remarkably lower $\Delta h$ values, as shown by Figure $2 \mathrm{a}(\Delta \mathrm{h}=1 \mathrm{~m})$. 


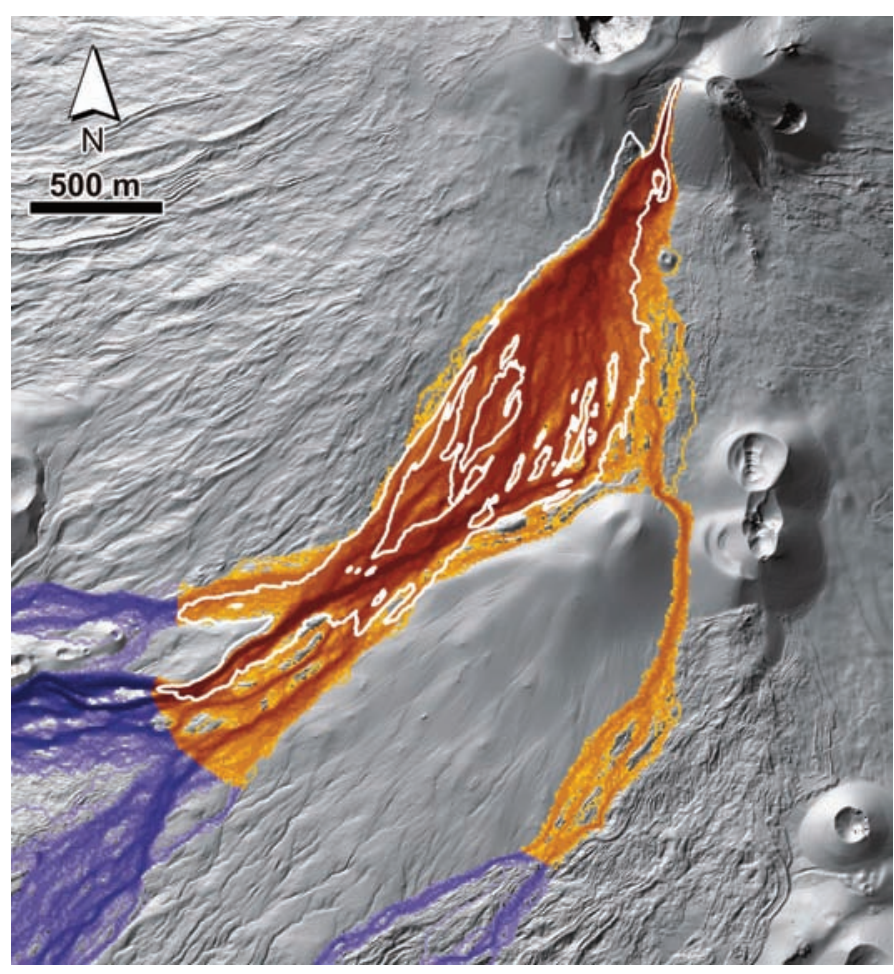

Figure 3. Comparison between real (white lines) and simulated (colored areas) lava-flow paths for the 2006 southern lava-flow field. Lighter and darker colors, higher or lower frequencies of simulated lava-flow passage, respectively. Red hues, areas located at a distance from the vent lower than the maximum distance attained by the real lava flows.

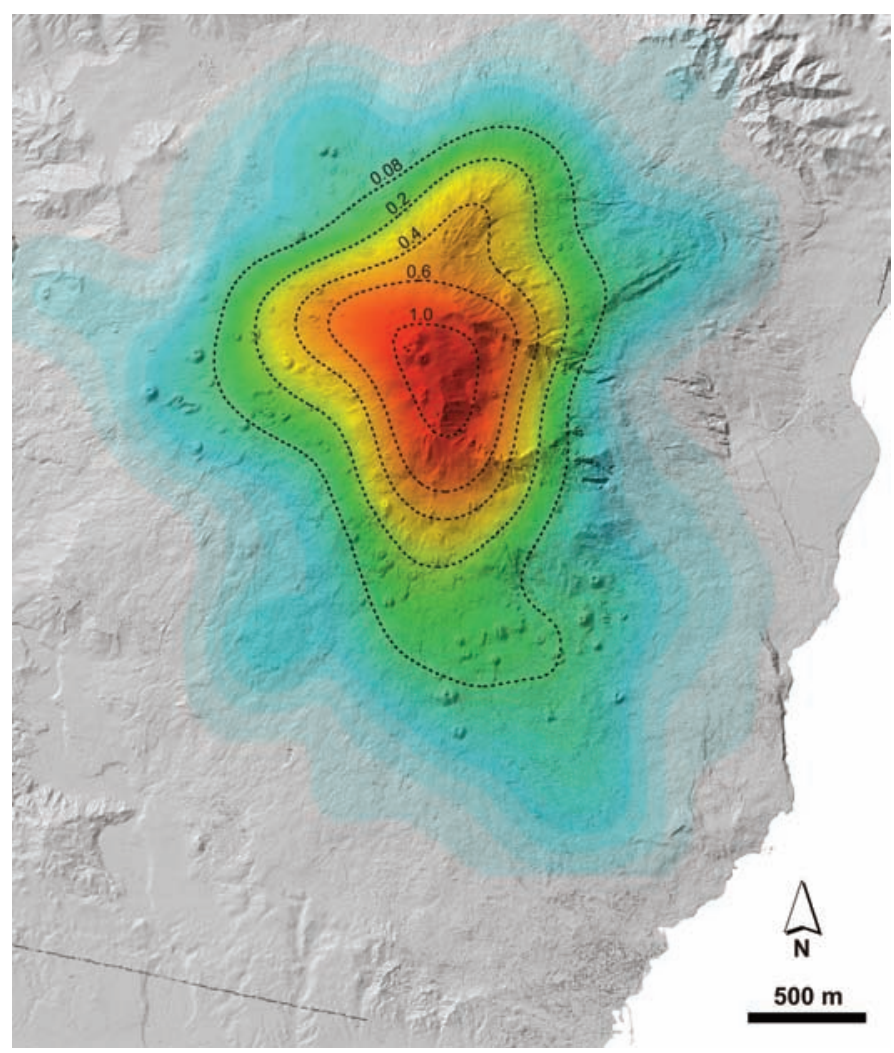

Figure 4. Probability density function for vent opening. Colors correspond to different probability density values expressed as percentages per square kilometer (black dashed contours are isolines).

\begin{tabular}{lccccc}
\hline Lava flow & $\begin{array}{c}\text { Fit, } \\
\boldsymbol{\mu}\end{array}$ & $\begin{array}{c}\text { Vent elev. } \\
(\mathbf{m})\end{array}$ & $\begin{array}{c}\mathbf{L} \\
(\mathbf{k m})\end{array}$ & $\begin{array}{c}\text { L ave } \\
(\mathbf{k m})\end{array}$ & $\begin{array}{c}\text { Max. } \\
\text { thickness } \\
(\mathbf{m})\end{array}$ \\
\hline 2001 south (LFS1) & 0.75 & 2100 & 6.4 & 7.3 & 40 \\
2002 north & 0.59 & 2100 & 7.4 & 7.3 & 25 \\
2004 & 0.78 & 2650 & 4.6 & 5.9 & 90 \\
2006 west & 0.77 & 3200 & 3.2 & 3.6 & 23 \\
2006 east & 0.68 & 3050 & 5.6 & 4.4 & 50 \\
\hline
\end{tabular}

Table 1.

\subsection{The DOWNFLOW approach for hazard-map costruction}

After the pioneering work of Wadge et al. [1994], several studies produced large databases of numerical simulations of lava flows for high resolution hazard maps [e.g. Felpeto et al. 2001, Crisci et al. 2008, Favalli et al. 2009b, Favalli et al. 2009c, Crisci et al. 2010, Tarquini and Favalli 2010]. To derive a quantitative lava-flow hazard map, in addition to the lava-flow simulation code, the following input data are necessary: (i) the topography of the volcano; (ii) the probability density function (pdf) of future vent opening; and (iii) the lava characteristics and the expected time-dependent effusions rates. In the case of DOWNFLOW, the effusion rates are not required as an input, although we need to know the expected length.

In terms of the DOWNFLOW formalism, the probability $P(x, y)$ that in the case of an eruption a generic point of coordinates $(x, y)$ will be inundated by a lava flow, can be written as:

$$
\begin{aligned}
& P(x, y)= \\
& \iint P_{\text {DOWNFLOW }}\left(x, y ; x^{\prime}, y^{\prime}\right) \cdot P_{L}(h, L) \cdot p_{v}\left(x^{\prime}, y^{\prime}\right) d x^{\prime} d y^{\prime}
\end{aligned}
$$

where, $h$ is the elevation of the point $\left(x^{\prime}, y^{\prime}\right) ; L$ is the distance along the lava flow between points $\left(x^{\prime}, y^{\prime}\right)$ and $(x, y)$; $P_{\text {DOWNFLOW }}\left(x, y ; x^{\prime}, y^{\prime}\right)$ is a probability that takes the value of 1 if the point $(x, y)$ is invaded by a lava flow that originates from the point $\left(x^{\prime}, y^{\prime}\right)$, and the value of 0 if it is not; $P_{L}(h, L)$ is the probability that a lava flow that vents from a point $\left(x^{\prime}, y^{\prime}\right)$ at an elevation $h$ will reach a distance $L$ downhill from the vent; and finally, $p_{v}\left(x^{\prime}, y^{\prime}\right)$ is the probability density function of a vent opening at the point $\left(x^{\prime}, y^{\prime}\right)$.

The exact meaning of the probability $P(x, y)$ depends directly on the definition of the probability density function of vent opening $p_{v}\left(x^{\prime}, y^{\prime}\right)$. In the case of Favalli et al. (2009b), the vent opening $\operatorname{pdf} \operatorname{pv}\left(x^{\prime}, y^{\prime}\right)$ had no intrinsic time scale, as it was simply the spatial density probability distribution for a new eruption, irrespective of the time of occurrence. The vent opening pdf used in the present study is shown in Figure 4 [LAVA Project 2010, Cappello et al. 2011a]. This was obtained using a Poisson distribution that considers a spatial density and a temporal component. The spatial probability density function was estimated through a Gaussian kernel, 
by considering the main volcanic structures at Mount Etna [Cappello et al. 2011b]. The temporal rate was evaluated using an approach based on the 'repose-time method' [Ho et al. 1991], with a time interval of 50 years.

For computational purposes, both the topography and the vent opening pdf are usually provided in a discrete form as regular grids. On the one hand, the topography is usually sampled in order to obtain a cell size in agreement with the computational demands of the simulation code (thus discretizing the values $x$ and $y$ ). On the other hand, the computational calculations of the surface integral in Equation (2) requires another discretization, which forces a computational vent spacing and thus turns the surface integral into a double sum over the discretized values of $x^{\prime}$ and $y^{\prime}$.

Here, by using DOWNFLOW, we have derived a lavaflow hazard map for Mount Etna that is specifically designed to be compared directly with similar lava-flow hazard maps derived using other lava-flow simulation codes [LAVA Project 2010]. The input topography used dates back to 2005 , and it has a cell-size of $10 \mathrm{~m}$ [Gwinner et al. 2007]. Favalli et al. [2009b, 2009c] have already presented lava-flow hazard maps for Mount Etna on a 10-m-spaced topography and with an 80-m computational vent spacing, for a total number of about 70,000 computational vents. Here we used a grid of computational vents that were constrained by the requirements of the simulation codes used for the other hazard maps [e.g. Rongo et al. 2011]. Therefore, we used a vent spacing of $500 \mathrm{~m}$ for a total number of only 4,290 computational vents, which lowers the resolution significantly with respect to that of Favalli et al. [2009b, 2009c].

\subsubsection{Lava-flow length distribution}

DOWNFLOW requires the specification of the length of each lava flow. For Mount Etna, the lengths are known for a large number of past lava flows, and it is well known that a negative correlation between vent elevation and length of the erupted lava flow holds (Figure 5a) [Lopes and Guest 1982]; i.e. lava flows that erupt high on the volcano tend to be shorter than those that erupt at lower elevations. A similar relationship emerged also at Mount Nyiragongo

a)
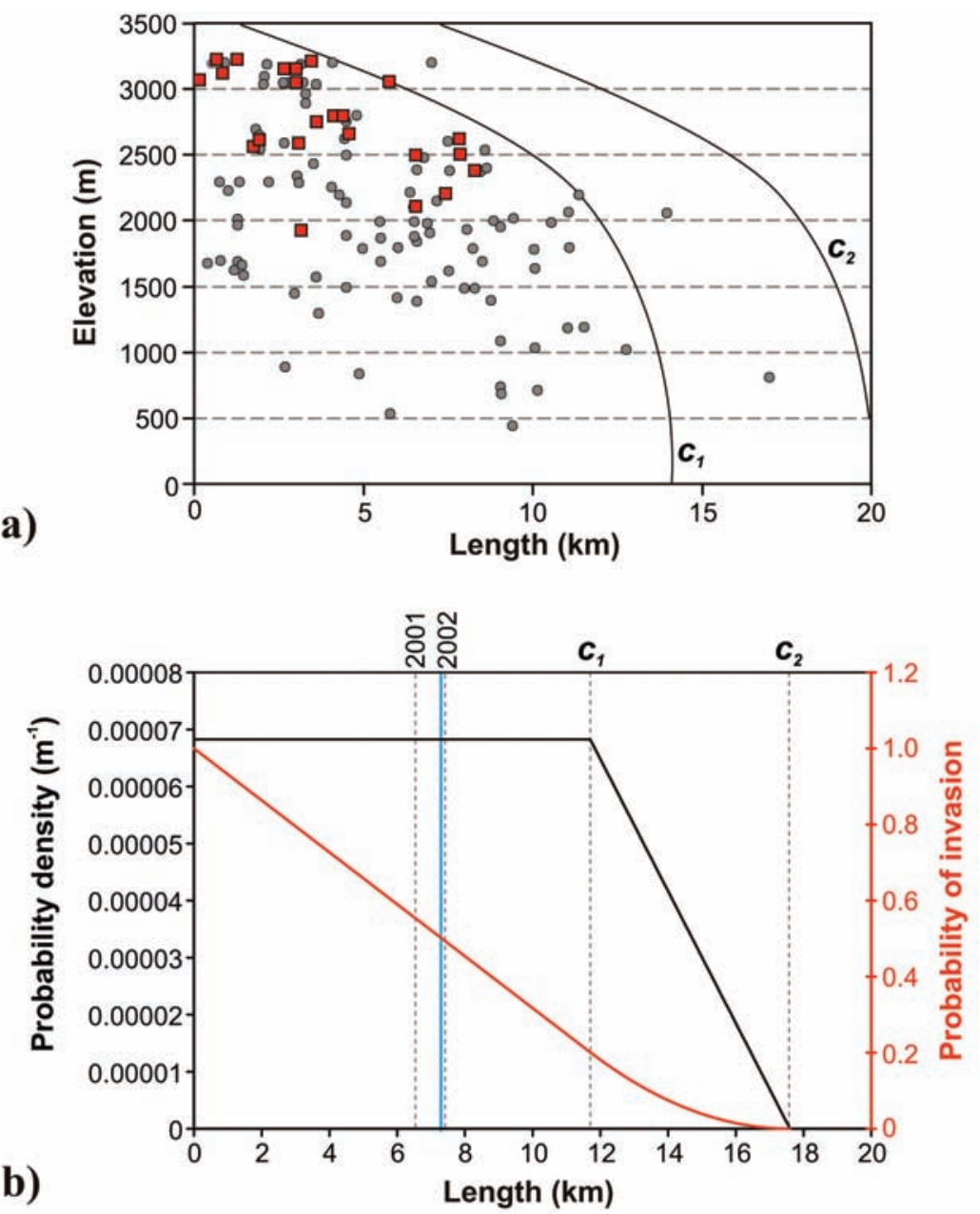

Figure 5. a) Distribution of lava-flow length versus vent elevation. Red squares, recent lava flows. $c_{1}$ delimits the area of the plot where there is a high, almost constant, concentration of points, while $c_{2}$ accounts for the sparse points outside $c_{1}$ and delimits the tail of the lava-flow length distribution. $\mathrm{b}$ ) In black, the probability to attain a length $L$ in the case of venting at an elevation of $2,100 \mathrm{~m}$. In red, the probability distribution for inundation by lava for a point downhill at a distance $L$ from the vent at an elevation of $2,100 \mathrm{~m}$. Blue line, the average expected length. Vertical dotted lines labeled 2001 and 2002 mark the lengths of the 2001 southern lava flow and the 2002 northern lava flow, respectively (both originated from vents at an elevation of $\sim 2,100 \mathrm{~m}$ ). 
[Favalli et al. 2009c] and Mount Cameroon [Favalli et al., in press], where a more limited number of lava flows are well known.

We used a statistical analysis of real lava-flow lengths to probabilistically define the expected lengths of the simulated lava flows (Figure 5). For each elevation, we assumed a constant probability for a lava flow to attain any given length, up to a length $L_{1}$. For greater lengths, we assumed that the distribution has a tail going linearly to zero from $L_{1}$ to $L_{2}$, which is the maximum length that can potentially be attained by a lava flow venting at a given elevation (Figure $5 \mathrm{~b}$ ). Drawing the key values $L_{1}$ and $L_{2}$ for all of the elevations, we obtain the two splines $c_{1}$ and $c_{2}$, respectively (Figure $5 \mathrm{a}$ ). According to our assumption, $c_{1}$ delimits the area where there is a high, almost constant, concentration of points in the plot of Figure 5a, while $c_{2}$ accounts for the sparse points outside $c_{1}$ that characterize the tail of the lava-flow length distribution.

For any given elevation, the average lava-flow length according to our distribution is given by $L=\left(L_{1}+L_{2}\right) / 4$. Table 1 gives the lengths of some of the recent lava flows, and the expected average lengths according to the adopted length distributions.

The lava-flow length distribution of Figure 5 a translates into a probability distribution for a point downhill at distance $L$ from the vent (at an elevation of 2,100 $\mathrm{m}$ in the example) to be invaded by the lava given in Figure $5 \mathrm{~b}$.

\subsection{Hazard map for Mount Etna}

Figure 6a shows the hazard map obtained by applying the above approach, the pdf for vent opening of Figure 4, and the law for the lengths of future lava flows of subsection 3.3.1 (Figure 5). It should be noted that the large vent spacing used here produces poor resolution in the summit region of the volcano, where the local convex topography tends to distribute lava flows in many almost equally probable diverging paths, rather than concentrating them into preferential channels. The highest peaks of probability of lava flow inundation are located in the Valle del Bove and on the western flank (upslope from the town of Bronte), but areas exposed to a high probability of being inundated by future lava flows are also widely scattered on the southeastern and southern flanks. To highlight areas of greatest hazard on the map, we segmented out in Figure $6 \mathrm{~b}$ the values greater than 0.015 (i.e. the three classes of highest probability of inundation), which obtained the areas with the highest probabilities of being inundated. From these, the downslope lobate limits of the high-hazard areas are delineated (Figure $6 \mathrm{~b}$ ).

Lobe 1 (north) is small and essentially upslope of 1,500 $\mathrm{m}$ asl, which highlights the overall low hazard of the entire northern sector of the volcano. Lobe 2 (northeast) comprises several narrow elements (i.e. corridors of higher probability) that reach $500 \mathrm{~m}$ asl; the village of Linguaglossa is directly impacted, while other villages, such as Piedimonte, might also be touched. Lobes 3 and 4 (east) channel the lava output downhill from the Valle del Bove, down to 100-200 m asl. Lobe 3 includes Milo and the suburbs of Giarre, while lobe 4 includes Zafferana Etnea and Santa Venerina. Although outside of the Valle del Bove, lobe 5 also extends eastwards, to affect the villages of Malopasso and Linera. Lobe 6 (southeast) is a relatively narrow but important channel, with a high probability of inundation by lava flows that reaches below $500 \mathrm{~m}$ asl, to touch small villages uphill of Acireale and a wide area to the south of Aci Platani. Lobe 7 (also southeast) extends down to the villages of San Gregorio and Valverde, and includes branches that might threaten the town of Catania; above $500 \mathrm{~m}$ asl, this lobe touches the villages of Nicolosi and Pedara, resulting in the lobe which poses one of the greatest threats to humans and properties. Lobe 8 (south) is partly connected with lobe 7 but points directly south, and it reaches down to about $500 \mathrm{~m}$ asl, where it encompasses the village of Belpasso. Lobe 9 extends south-westwards between $1,000 \mathrm{~m}$ asl and $500 \mathrm{~m}$ asl, to touch the village of Ragalna. Lobe 10 is a wide fan that covers most of the southwest flank of the Mount Etna volcano, and the highest probabilities of inundation by future lava flows within it are essentially confined above $1,000 \mathrm{~m}$ asl, which testifies that as a whole, this sector of the volcano has a lower hazard with respect to the eastern and southern sectors (e.g. from lobe 3 to 9). Lobe 11 encompasses much of the western sector of the volcano and it is made of several sub-lobes that are braiding among each other to form a wide fan; this lobe extends below 1,000 $\mathrm{m}$ asl, to encompass the village of Bronte.

The assessment of the reliability of a lava-flow hazard map is a hot topic in volcanology. Favalli et al. [2009b] compared lava-flow hazard maps for Mount Etna with actual lava flow emplacements from before and after the time of the topography used as reference. Such a comparison outlines some qualitative relationships between hazard maps and real lava flows.

Recently, two techniques have been proposed that were aimed at quantifying the reliability of lava-flow hazard maps [Crisci et al. 2010, Cappello et al. 2011b]. Both of these methods approach this topic from a theoretical point of view. In contrast, a straightforward evaluation can be derived by the study of the evolution of the lava-flow hazard maps of Tarquini and Favalli [2010]. These authors showed how short-term morphological changes at Mount Etna are reflected in changes in the maps of the susceptibility to lavaflow inundation.

A good test for the reliability of a lava-flow hazard map is given by comparing it with the coverage of new lava-flow emplacements. In this way, when the time series of the hazard maps of Figure 7 are compared with the maps of lava-flow emplacements in between, this gives clear indications of the 

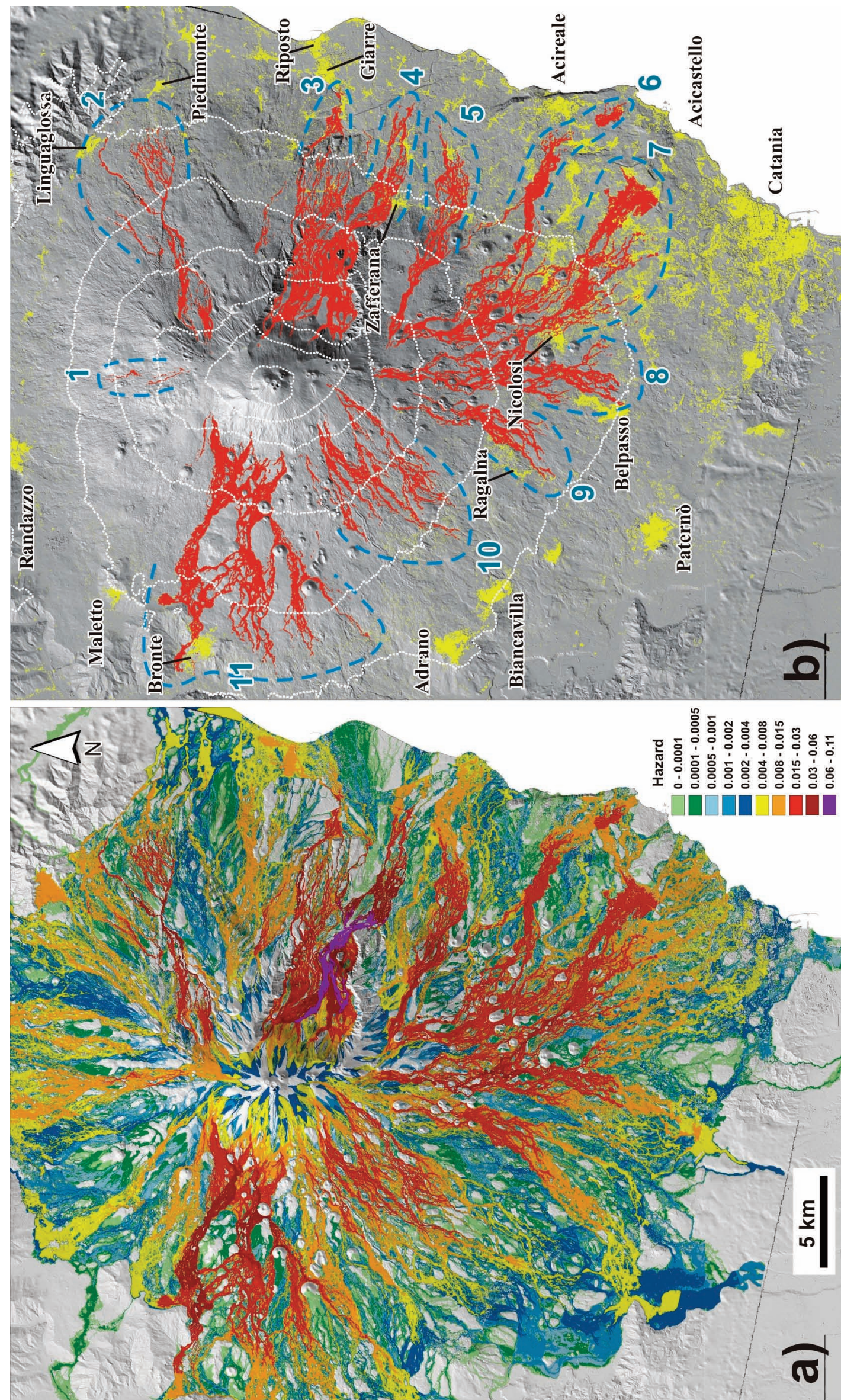

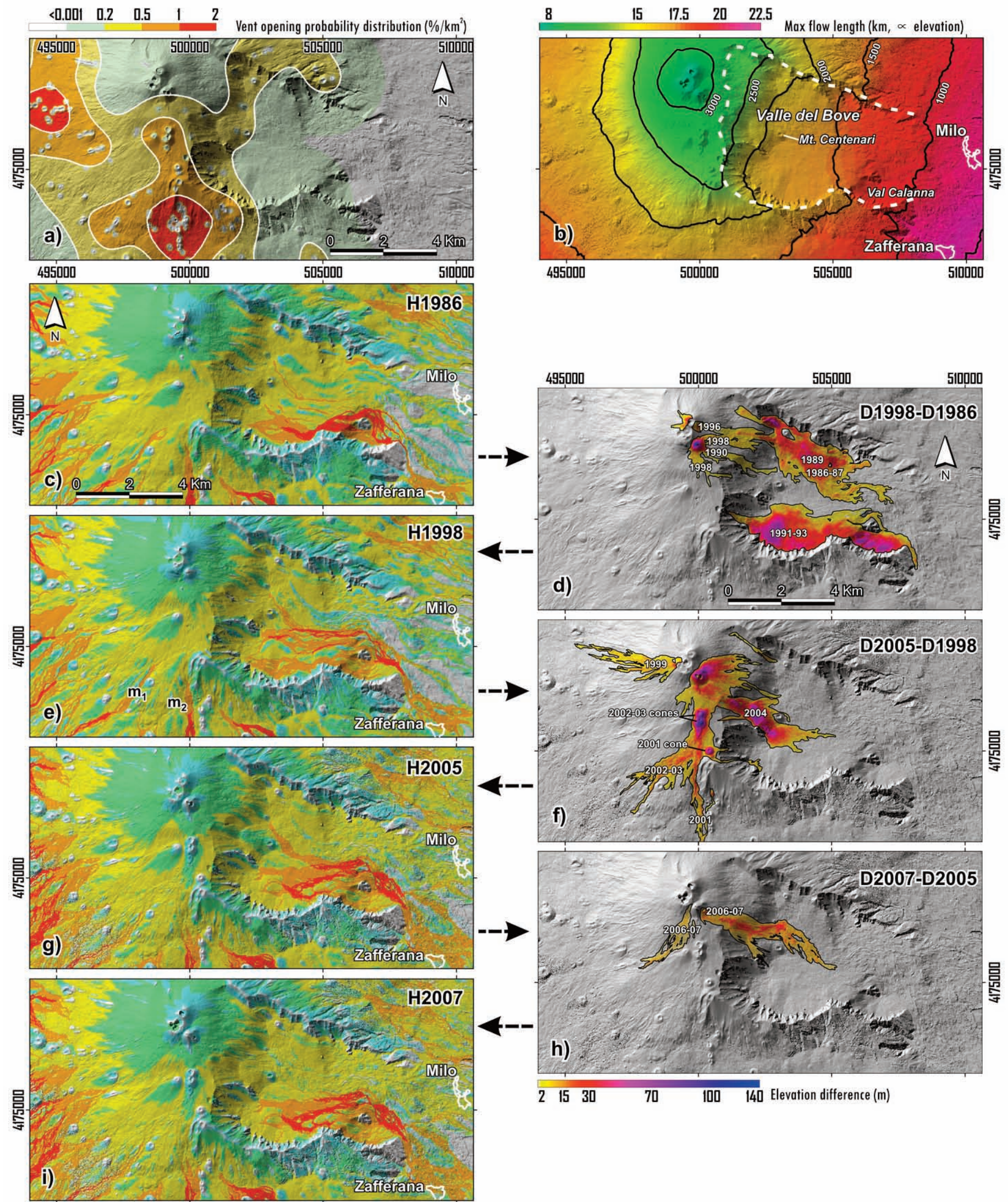

$\begin{array}{llllll}2 & 15 & 30 & 70 & 100 & 140 \text { Elevation difference }(\mathrm{m})\end{array}$

$>0 \quad<.01 \quad 0.1 \quad 1 \quad 2 \quad 5$ Probability of invasion (percent)

Figure 7. a) Map of the vent-opening probability used in Equation (1) (see main text), modified after Tarquini and Favalli [2010]; b) Map of the maximum expected length for future lava flows as a function of the vent elevation (modified after Tarquini and Favalli [2010]); c), e), g), i) Hazard maps of a portion of Mount Etna including the Valle del Bove, based on the 1986, 1998, 2005 and 2007 DEMs, respectively. d), f), h) Maps of the differences between the 1998 and 1986 DEMs, 2005 and 1998 DEMs, and 2007 and 2005 DEMs, respectively. Colored areas represent the main lava flows and scoria cones formed over each time interval (the noise outside these main changes has been masked out). 
effectiveness of the method. Figure $7 \mathrm{a}, \mathrm{b}$ show the pdf for vent opening and the map of the maximum expected lavaflow length, respectively, that were used to derived the hazard maps of Figure7c, e, g, i (modified after Favalli et al. [2009b] and Tarquini and Favalli [2010]). An 80-m-cell-size grid of computational vents was adopted here, which covers the portion of Mount Etna shown in Figure 7. The hazard maps of Figure7c, e, g, i refer to 10-m-resolution topographic datasets that were acquired in 1986 [Favalli et al. 1999], 1998 [Tarquini et al. 2007], 2005 [Favalli et al. 2009a] and 2007 [Favalli et al. 2009a], respectively (modified after Tarquini and Favalli [2010]). Figure 7d, f, h are elevation difference maps between the 1998-1986, 2005-1998 and 2007-2005 topographies, respectively (modified after Tarquini and Favalli [2010]). Note that with time the positions of the local maximum hazards change within the Valle del Bove. Figure 7c shows a clear maximum in the southern-most sector of Valle del Bove and Val Calanna, and Figure $7 \mathrm{~d}$ shows that the maximum was actually covered by the 1991-93 eruption; the same panel shows extensive lava-flow emplacements in the northern sector of Valle del Bove, whereas Figure $7 \mathrm{c}$ shows only a moderate probability of lava-flow inundation. In evaluating these results, we have to note that the pdf of Figure 7 a does not adequately take into account vent opening in the summit area, as it is representative only for the flank eruptions [Favalli et al. 2009b]. Figure7e shows that in 1998, the sector of the Valle del Bove with the highest probability of being inundated by future lava flows was the central one, east of Mount Centenari. Figure $7 \mathrm{f}$ confirms that the first sector of the Valle del Bove that was covered by new lava flows was actually the central one (the 2004 eruption). In addition, the lower portion of Figure 7e shows two narrow maxima (Figure $7 \mathrm{e}, m_{1}, m_{2}$ ) that head southwards and southwestwards, while Figure $7 \mathrm{f}$ confirms that both of these maxima were indeed broadly covered by the subsequent 2001 and 2002-03 eruptions. Finally, a comparison of Figure $7 \mathrm{~g}$ and $7 \mathrm{~h}$ also shows that the emplacements of the 2006 lava-flow fields are in agreement with the local maxima of the probability of lava-flow inundation.

Figure $8 \mathrm{a}, \mathrm{b}$ show again two hazard maps of a part of Mount Etna. These maps were calculated using the grid of computational vents, the pdf for vent opening, and the law for lava-flow length used to obtain the map of Figure 6a. The only difference between the two maps of Figure $8 a, b$ is in the topography that was used as boundary conditions for the simulations: a 10-m-resolution topography that was acquired in 2005 was used for Figure 8a [Gwinner et al. 2007], while a 10 -m-resolution LIDAR-derived topography that was acquired in 2007 was used for Figure 8b [Favalli et al. 2009a]. Figure $8 \mathrm{c}$ shows the differences between the probabilities of the hazard maps of Figure 8a, b. The white lines in Figure 8c delineate the coverage of the 2006 flow-field emplacements towards the east and southwest of the Southeast Crater. The effect of this emplacement is a strong decrease in the probability of lava-flow inundation within the flow field boundaries, which is accompanied by local increases just outside these boundaries.

\section{Discussion and conclusions}

This analysis of an evolving compound lava-flow field carried out using the 2006 Airborne LIDAR survey at Mount Etna (Figure 1) allows the quantitative description of the emplacement distribution. The outcomes from this analysis have several direct implications for the simulation of Etnean compound lava fields.

First of all, the imaged field consists of several active lava channels that have widths of between $5 \mathrm{~m}$ and $15 \mathrm{~m}$. Such channel dimensions imply that the computation cell size to be used by simulation codes that solve the full physical equations for lava-flow transport must be considerably smaller than $5 \mathrm{~m}$ or $10 \mathrm{~m}$, which are the typically used cell sizes [e.g. Del Negro et al. 2008, Proietti et al. 2009].

Figure $1 \mathrm{~b}$ shows the six simultaneously active flow channels that were transporting the lava with pulsing volume rates ranging from almost zero (Figure $1 \mathrm{~b}$, channel 1.2) up to $3 \mathrm{~m}^{3} / \mathrm{s}$ (Figure 1b, channel 2.2); these feed flow fronts that advanced with velocities that ranged from $3 \mathrm{~m} / \mathrm{h}$ to $90 \mathrm{~m} / \mathrm{h}$. In turn, these channels were fed by three ephemeral vents (Figure 1b, 1 to 3 ) which were distributing the total effusion rate. With the currently available computational resources, it is hardly possible to reproduce such a complicated transport mechanism in a deterministic way. However, computational resources are not the only limit: indeed, the input and boundary conditions required for the simulation were affected by very high errors. Effusion rates, and lava composition and characteristics (such as emission rate, temperature, viscosity) are not easy to measure, making their continuous monitoring in time impractical.

The calculated daily TADRs using LIDAR data have errors of under $1 \%$, which are very accurate when compared with other methods that typically provide values affected by errors of $\sim 50 \%$ [Harris et al. 2007]. Harris et al. [2010] used the LIDAR-derived TADR that are available for flow fields active on Etna in 2004 and 2006 as the "ground-truths" for the calibration of the relationships between TADR, lava flow insulation, and area. This has allowed a simple means to convert satellite-data-derived lava-flow areas to TADRs, which is important when direct field measurements are not available. Nevertheless, satellite data still provide TADRs that cannot be considered accurate enough to reliably drive realtime numerical simulations during an ongoing eruptive event. Indeed, for such a task, not even the LIDAR-derived discharge rates are accurate enough, as they are affected by errors in the order of $50 \%$ when calculated over time scales of a few tens of minutes.

At Mount Etna, the lava flows usually start as single flow 


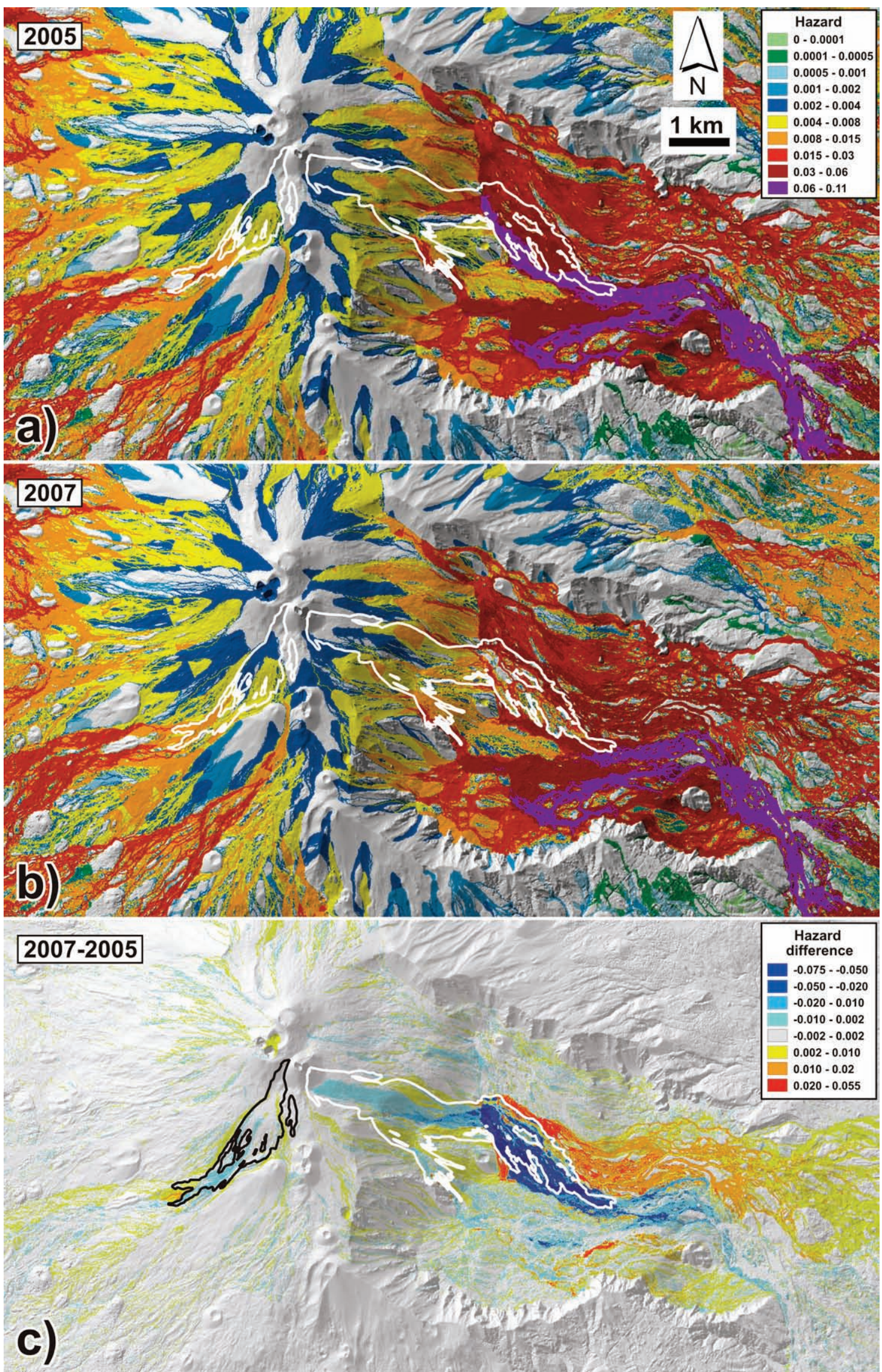

Figure 8. a), b) Hazard maps of a portion of Mount Etna that includes the Valle del Bove, based on the 2005 [Gwinner et al. 2007] and 2007 [Favalli et al. 2009a] DEMs, respectively. Input data for these maps were the pdf for vent opening of Figure 4 and the law for the expected lengths of the lava flows of Figure 5a. c) Difference map between the maps of panels b) and a). White or black lines delimit the lava-flow emplacements during the 2006 eruption. 
units, although if an eruption lasts long enough, these single flows invariably evolve into compound flows. The number of flow units that contribute to a final flow field can easily reach several tens, or even hundreds. Each flow unit follows its own path as the lava moves down-slope, and the flows that develop in the rear portion of the field will encounter a topographic slope that has already been modified by the emplacement of earlier lava flows in the series. Hence, the growth of a compound lava-flow field arises from a complex process that can be summarized as multiple emplacement over successively modified pre-eruption topographies. This is the same basic principle upon which the DOWNFLOW code is based. DOWNFLOW derives the areas that might be inundated as the sum of a number of paths over a randomly varied initial topography [Favalli et al. 2005].

The DOWNFLOW probabilistic code is effective for the construcion of hazard maps at Mount Etna for several reasons. It can be easily and straightforwardly calibrated to best fit the final coverage of Etnean composite lava-flow fields. Also, it does not need information about the chemical or rheological properties of the erupted lava, nor does it require knowledge of time-dependent effusion rates, which are only known in a few cases and which are greatly affected by errors. Instead, the DOWNFLOW probabilistic code needs only the statistics of the lava-flow lengths, which are available for a large number of lava flows on Mount Etna. DOWNFLOW needs only a short computational time, so that a high number of possible vent locations can be considered, and the scenarios can be updated in relatively short times. As a probabilistic code (as opposed to a deterministic code), DOWNFLOW intrinsically considers perturbations of the original topography; thus, the result is only marginally affected by the resolution and/or errors of the input topography [e.g. Wright et al. 2008]. According to Renschler [2005], although complex process-based models are useful in research, models used for management decisions, such as volcanic hazard mitigation by civil protection personnel, need to be simple and unpretentious, with few data requirements and clearly stated assumptions. Thus, the hazard map obtained here for Mount Etna using the DOWNFLOW probabilistic code constitutes a simple operative tool for hazard mitigation (e.g. Figure 6b).

It is of note that the simplicity of the DOWNFLOW model has been the basis for the development of novel paradigms and procedures to improve and extend hazard and risk analyses [Favalli et al. 2009d]. The hazard maps presented here and in Favalli et al. [2009b], combined with the risk maps presented in Favalli et al. [2009d], provide a thorough description of the hazard and risk posed by future lava flows on Mount Etna.

These DOWNFLOW-based maps can be readily used to mitigate hazards and risks not just before, but also at the onset of and during future effusive crises at Mount Etna.
Acknowledgements. This study was partially funded by the Italian Dipartimento della Protezione Civile in the framework of a 2007-2009 agreement with the Istituto Nazionale di Geofisica e Vulcanologia (INGV). We thank Dr. David R. Sherrod and an anonymous reviewer, as their reviews of our original manuscript helped us to greatly improve its quality.

\section{References}

Allard, P., B. Behncke, S. D'Amico, M. Neri and S. Gambino (2006). Mount Etna 1993-2005: Anatomy of an evolving eruptive cycle, Earth Science Reviews, 78 (1-2), 85-114; doi: 10.1016/j.earscirev.2006.04.002.

Bailey, J.E., A.J.L. Harris, J. Dehn, S. Calvari and S.K. Rowland (2006). The changing morphology of an open lava channel on Mt. Etna, B. Volcanol., 68, 497-515.

Baltsavias, E.P. (1999). Airborne laser scanning: basic relations and formulas, ISPRS J. Photogramm., 54, 199-214.

Behncke, B., S. Calvari, S. Giammanco, M. Neri and H. Pinkerton (2008). Pyroclastic density currents resulting from the interaction of basaltic magma with hydrothermally altered rock: an example from the 2006 summit eruptions of Mount Etna, Italy, B. Volcanol., 70, 12491268; doi: 10.1007 / s00445-008-0200-7.

Bisson, M., B. Behncke, A. Fornaciai and M. Neri (2009). Lidar-based digital terrain analysis of an area exposed to the risk of lava flow invasion: the Zafferana Etnea territory, Mt. Etna (Italy), Nat. Hazards, 50, 321-334; doi: 10.1007/s11069-009-9346-7.

Calvari, S. and H. Pinkerton (2002). Instabilities in the summit region of Mount Etna during the 1999 eruption, B. Volcanol., 63, 526-535.

Cappello, A., A. Vicari and C. Del Negro (2011a). Retrospective validation of a lava-flow hazard map for Mount Etna volcano, Annals of Geophysics, 54 (5), 634-640 (this issue).

Cappello, A., A. Vicari and C. Del Negro (2011b). Assessment and modeling of lava flow hazard on Etna volcano, B. Geofis. Teor. Appl., 52 (2), 299-308; doi: 10.4430/bgta0003.

Crisci, G.M., G. Iovine, S. Di Gregorio and V. Lupiano (2008). Lava flow hazard on the SE flank of Mt. Etna (southern Italy), J. Volcanol. Geoth. Res., 177, 778-796.

Crisci, G.M., M.V. Avolio, B. Behncke, D. D'Ambrosio, S. Di Gregorio, V. Lupiano, M. Neri, R. Rongo and W. Spataro (2010). Predicting the impact of lava flows at Mount Etna, Italy, J. Geophys. Res., 115, B04203; doi: 10.1029/2009JB 006431.

Csatho, B., T. Schenk, P. Kylec, T. Wilsond and W.B. Krabille (2008). Airborne laser swath mapping of the summit of Erebus volcano, Antarctica: applications to geological mapping of a volcano, J. Volcanol. Geoth. Res., 177, 531548; doi: 10.1016/j.jvolgeores.2008.08.016.

Del Negro, C., L. Fortuna, A. Hérault and A. Vicari (2008). Simulations of the 2004 lava flow at Etna volcano using the magflow cellular automata model, B. Volcanol., 70, 805-812; doi: 10.1007/s00445-007-0168-8.

Favalli, M., F. Innocenti, M.T. Pareschi, G. Pascquarè, F. Maz- 
zarini, S. Branca, L. Cavarra and A. Tibaldi (1999). The DEM of Mt. Etna: geomorphological and structural implications, Geodin. Acta, 12 (5), 279-290.

Favalli, M., M.T. Pareschi, A. Neri and I. Isola (2005). Forecasting lava flow paths by a stochastic approach, Geophys. Res. Lett., 32, L03305; doi: 10.1029/2004GL021718.

Favalli, M., A. Fornaciai and M.T. Pareschi (2009a). LIDAR strip adjustment: application to volcanic areas, Geomorphology, 111, 123-135; doi:10.1016/j.geomorph.2009.04.010.

Favalli, M., F. Mazzarini, M.T. Pareschi and E. Boschi (2009b). Topographic control on lava flow paths at Mt. Etna (Italy): implications for hazard assessment, J. Geophys. Res., 114, F01019; doi: 10.1029/2007JF000918.

Favalli, M., G.D. Chirico, P. Papale, M.T. Pareschi and E. Boschi (2009c). Lava flow hazard at Nyiragongo volcano, D.R.C. Part 1, Model calibration and hazard mapping, B. Volcanol., 71, 363-374; doi: 10.1007/s00445-008-0233-y.

Favalli, M., S. Tarquini, A. Fornaciai and E. Boschi (2009d). A new approach to risk assessment of lava flow at Mount Etna, Geology, 37, 1111-1114; doi: 10.1130/G30187A.

Favalli, M., A. Fornaciai, F. Mazzarini, A. Harris, M. Neri, B. Behncke, M.T. Pareschi, T. Tarquini and E. Boschi (2010a). Evolution of an active lava flow field using a multitemporal LIDAR acquisition, J. Geophys. Res, 115, B11203; doi: 10.1029/2010JB007463.

Favalli, M., A.J.L. Harris, A. Fornaciai, M.T. Pareschi and M. Mazzarini (2010b). The distal segment of Etna's 2001 basaltic lava flow, B. Volcanol., 72, 119-127.

Favalli, M., S. Tarquini, P. Papale, A. Fornaciai and E. Boschi. Lava flow hazard and risk at Mt. Cameroon volcano, B. Volcanol., (in press, preview available online); doi: 10.1007/s00445-011-0540-6.

Felpeto, A., V. Arana, R. Ortiz, M. Astiz and A. Garcia (2001). Assessment and modelling of lava flow hazard on Lanzarote (Canary Islands), Nat. Hazards, 23, 247-257.

Fornaciai, A., B. Behncke, M. Favalli, M. Neri, S. Tarquini and E. Boschi (2010a). The rapid growth and aging of cinder cones: examples from the 2001 and 2002-2003 eruptions of Mount Etna (Italy), B. Volcanol., 72, 1209-1222; doi: 10.1007/s00445-010-0388-1.

Fornaciai, A., M. Bisson, P. Landi, F. Mazzarini, and M.T. Pareschi (2010b). A LIDAR survey of Stromboli volcano (Italy): DEM-based geomorphology and intensity analysis, Intl. J. Remote Sens., 31, 3177-3194; doi: 10.1080/0143 1160903154416.

Guest, J.E., C.R.J. Kilburn, H. Pinkerton and A.M. Duncan (1987). The evolution of lava flow fields: observations of the 1981 and 1983 eruptions of Mount Etna, Sicily, B. Volcanol., 49, 527-540.

Gwinner, K., M. Coltelli, J. Flohrer, R. Jaumann, K.D. Matz, M. Marsella, T. Roatsch, F. Scholten and F. Trauthan (2007). The HRSC-AX Mt. Etna project: high-resolution orthoimages and $1 \mathrm{~m}$ DEM at regional scale, ISPRS Com- mission Technique I. Symposium (Paris/Marne-laVallée, France, July 3-6, 2006), Revue Française de Photogrammétrie et de Télédétection, 183, 61-66.

Harris, A., M. Favalli, F. Mazzarini and M.T. Pareschi (2007). Best-fit results from application of a thermo-rheological model for channelized lava flow to high spatial resolution morphological data, Geophys. Res. Lett., 34, L01301; doi: 10.1029/ 2006GL028126.

Harris, A., M. Favalli, A. Steffke, A. Fornaciai and E. Boschi (2010). Relation between lava discharge rate, flow area and insulation for use with satellite data, Geophys. Res. Lett., 37, L20308; doi: 10.1029/2010GL044683.

Ho, C-H., E.I. Smith, D.L. Feuerbach and T.R. Naumann (1991). Eruptive calculation for the Yucca Mountain site, USA: statistical estimation of recurrence rates, B. Volcanol., 54, 50-56.

Höfle, B. and N. Pfeifer (2007). Correction of laser scanning intensity data: data and model-driven approaches, ISPRS J. Photogramm., 62, 415-433.

Kilburn, C.R.J. and R.M.C. Lopes (1988). The growth of aa lava flow fields at Mount Etna, Sicily, J. Geophys. Res., 93, B12, 14759-14772.

Lautze, N.C., A.J.L. Harris, J.E. Bailey, M. Ripepe, S. Calvari, J. Dehn and S. Rowland (2004). Pulsed lava effusion at Mount Etna during 2001, J. Volcanol. Geoth. Res., 137, 231-246.

LAVA Project (2010). Realization of the lava flow invasion hazard map at Mt Etna and methods for its dynamic update, Coordinators C. Del Negro and S. Gresta, INGVDPC Agreement 2007-2009, Final Scientific Report, 1 May 2008 - 31 May 2010, 190 pp.

Lopes, R. and J. E. Guest (1982). Lava flows on Etna, a morphometric study, In: The Comparative Study of Planets, edited by A. Coradini and M.D. Fulchignoni, Dordrecht, Netherlands, D. Reidel, 441-458.

Mazzarini, F., M.T. Pareschi, M. Favalli, I. Isola, S. Tarquini and E. Boschi (2005). Morphology of basaltic lava channels during the Mt. Etna September 2004 eruption from airborne laser altimeter data, Geophys. Res. Lett., 32, L04305; doi: 10.1029/2004Gl021815.

Mazzarini, F., M.T. Pareschi, M. Favalli, I. Isola, S. Tarquini and E. Boschi (2007). Lava flow identification and aging by means of LIDAR intensity: the Mt. Etna case, J. Geophys. Res., 112, B02201; doi: 10.1029/2005JB004166.

Neri, M., F. Mazzarini, S. Tarquini, M. Bisson, I. Isola, B. Behncke and M.T. Pareschi (2008). The changing face of Mount Etna's summit area documented with LIDAR technology, Geophys. Res. Lett., 35, L09305; doi: 10.1029/2008GL033740.

Proietti, C., M. Coltelli, M. Marsella and E. Fujita (2009). A quantitative approach for evaluating lava flow simulation reliability: LavaSIM code applied to the 2001 Etna eruption, Geochem. Geophys. Geosyst., 10, Q09003; doi: 
10.1029/2009GC002426.

Renschler, C.S. (2005). Scales and uncertainties in using models and GIS for volcano hazard prediction, J. Volcanol. Geoth. Res., 139, 73-87; doi: 10.1016/j.jvolgeores.2004. 06.016 .

Rongo, R., W. Spataro, D. D'Ambrosio, M.V. Avolio, G.A. Trunfio and S. Di Gregorio (2008). Lava flow hazard evaluation through cellular automata and genetic algorithms: an application to Mt Etna volcano, Fundamenta Informaticae, 87, 1-21.

Rongo, R., M.V. Avolio, B. Behncke, D. D'Ambrosio, S. Di Gregorio, V. Lupiano, M. Neri, W. Spataro and G.M. Crisci (2011). Defining high-detail hazard maps by a cellular automata approach: application to Mount Etna (Italy), Annals of Geophysics, 54 (5), 568-578 (this issue).

Tarquini, S., I. Isola, M. Favalli, F. Mazzarini, M. Bisson, M.T. Pareschi and E. Boschi (2007). TINITALY/01: a new triangular irregular network of Italy, Annals of Geophysics, 50 (3), 407-425.

Tarquini, S. and M. Favalli (2010). Changes of the susceptibility to lava flow invasion induced by morphological modifications of an active volcano: the case of Mount Etna, Italy, Nat. Hazards, 54, 537-546; doi: 10.1007/s1106 9-009-9484-y.

Ventura, G. and G. Vilardo (2007). Emplacement mechanism of gravity flows inferred from high resolution LIDAR data: The 1944 Somma-Vesuvius lava flow (Italy), Geomorphology, 95, 223-235; doi: 10.1016/j.geomorph.2007. 06.005 .

Wadge, G. (1978). Effusion rate and the shape of aa lava flowfield on Mount Etna, Geology, 6, 503-506.

Wadge, G., P.A.V. Young and I.J. McKendrick (1994). Mapping lava flow hazard using computer simulation, J. Geophys. Res., 99, 489-504; doi: 10.1029/93JB01561.

Wagner, W., A. Ullrich, V. Ducic, T. Melzer and N. Studnicka (2006). Gaussian decomposition and calibration of a novel small-footprint full-waveform digitising airborne laser scanner, ISPRS J. Photogramm., 60, 100-112.

Wehr, A. and U. Lohr (1999). Airborne laser scanning - an introduction and overview, ISPRS J. Photogramm., 54, 68-82.

Wright, R., H. Garbeil and A.J.L. Harris (2008). Using infrared satellite data to drive a thermo-rheological/stochastic lava flow emplacement model: A method for near-real-time volcanic hazard assessment, Geophys. Res. Lett., 35, L19307; doi: 10.1029/2008GL035228.

\footnotetext{
^Corresponding author: Massimiliano Favalli, Istituto Nazionale di Geofisica e Vulcanologia, Sezione di Pisa, Pisa, Italy; email: favalli@pi.ingv.it. 